\title{
Life Course Offending Pathways Across Gender and Race/Ethnicity
}

\author{
Lisa M. Broidy ${ }^{1}$. Anna L. Stewart ${ }^{1}$. \\ Carleen M. Thompson ${ }^{1}$ - April Chrzanowski ${ }^{1}$. \\ Troy Allard $^{1} \cdot$ Susan M. Dennison ${ }^{1}$
}

Received: 17 November 2014 / Revised: 26 March 2015 / Accepted: 10 April 2015 /

Published online: 25 April 2015

(C) Springer International Publishing AG 2015

\begin{abstract}
Purpose This paper aims to refine our understanding of life course offending patterns across gender and race/ethnicity and to advance work in this area by examining how gender and race/ethnicity interact to influence life course offending patterns.

Methods We use criminal justice system data to construct a longitudinal offending cohort that includes all individuals born in 1983/1984 with at least one court finalization for a criminal offense in the state of Queensland between the ages of 10 and 25 years. The data include 41,280 offenders $(25.6 \%$ female; $8.9 \%$ Indigenous Australian) responsible for 209,872 offenses $(M=5.08, \mathrm{SD}=12.31)$. Coupling these data with state-level census data for those born in 1983/1984 $(N=129,782)$, we estimate cohort offending rates overall and disaggregated by gender and race/ethnicity both independently and jointly. Focusing on the offenders, we use semiparametric groupbased modeling to identify the number and longitudinal distributions of offending trajectories within the cohort and compare how subgroups defined by gender, Indigenous status, and their combination sort into these trajectories.

Results Most of the birth cohort has little to no contact with the criminal justice system through age 25. However, patterns are not uniform across gender or race/ethnicity, with males and Indigenous Australians most likely to fit the serious and chronic offending trajectories. Gender and race/ethnicity also interact to influence offending patterns with non-Indigenous females significantly more likely than any other group to avoid system contact, while Indigenous males have comparatively exaggerated rates of contact. Moreover, Indigenous females offend in ways more similar to non-Indigenous males than females and, in some instances, evidence even more serious offending.
\end{abstract}

Lisa M. Broidy

1.broidy@griffith.edu.au

1 School of Criminology and Criminal Justice, Griffith University, 176 Messines Ridge Rd, Mt Gravatt, Queensland 4122, Australia 
Conclusions Developmental and life course models should highlight not just the operant developmental dynamics across key life stages or the relevant age-graded risk and protective factors at play, but also how gender and race/ethnicity condition these processes both independently and jointly.

Keywords Developmental and life course theory $\cdot$ Gender $\cdot$ Race/ethnicity · Offending trajectories

\section{Introduction}

Advances in our understanding of the developmental and life course patterns and processes that characterize and shape offending trajectories are reliant on large, longitudinal data collection efforts. The core theories in this area are assessed against, and revised in concert with, patterns that emerge from longitudinal datasets tracking a select population, birth, or offending cohort over time. Moffitt's [71] dual trajectory theory reflects the offending patterns that unfold in her New Zealand birth cohort. Similarly, Farrington's [34] Integrated Cognitive Antisocial Potential Theory evolved in concert with his work following the sample that comprises the Cambridge Study in Delinquent Development. Thornberry's [94] interactional theory emerged in parallel with his work on the Rochester Youth Development Survey and was revised as the data accumulated [95]. Building from control theories and working with data initially collected by Glueck and Glueck, Sampson and Laub [86] developed an age-graded theory of informal social control, which they revised to include elements of personal agency based on follow-up data with a subsample of the men from the initial delinquent study cohort [59]. Giordano et al. [44] and Maruna [66] both develop theories of agency and cognitive change, tested against and refined to reflect qualitative data from offending cohorts.

Subsequent research tests the broad applicability of these theoretical propositions in other samples to establish their generalizability both locally and cross-nationally. The bulk of this work is based on data relating to male offenders. Even those studies with large representative samples of males and females typically lack the quantitative capacity to evaluate the nuances of female offending patterns or offending patterns disaggregated by race/ethnicity. This is because, even when representative, female and minority subsamples are generally small, complicating efforts to distill patterns and processes that might be gender or race/ethnicity specific. Even less common is work examining the joint contributions of gender and race/ethnicity to longitudinal offending patterns and processes.

Our aim in this paper is to examine how gender and race/ethnicity interact to shape life course offending patterns. Although our approach is largely descriptive, this is an important step in theory building and articulating the intersectionality of gender and race/ethnicity in life course offending patterns. Few studies have examined the impact of gender and race/ethnicity on life course offending [23, 28, 31, 57]. Furthermore, in recent years, multiracial feminist scholars have focused attention not only on the gender differences in offending but also on understanding intersecting inequalities, particularly the intersections between race/ethnicity and gender and their combined influence on crime [23]. There is a dearth of research examining the intersection between 
race/ethnicity and gender over the life course and theoretical development on this front is similarly limited.

This gap in the developmental and life course literature on offending patterns and processes is notable because work to date indicates that, at least in cross section, the interaction of gender and race/ethnicity can mute disparities in offending that are significant when examining gender or race/ethnicity in isolation. For instance, data from US samples suggests that Black females evidence significantly higher rates of violent offending than White females $[47,87]$ and, in some instances, also show higher rates than White males [13]. These findings reinforce the importance of intersectionality for our understanding of the influence of gender and race/ethnicity on offending. While most often conceptualized as independent statuses for theoretical and analytic purposes, this strategy masks the ways in which gender and race/ethnicity jointly influence structural and individual-level processes. Theoretical and empirical work on intersectionality reinforces the difficulty of disentangling these processes and highlights their relational and reinforcing effects $[49,50,85,98]$. In criminology, qualitative work outlines the important ways in which gender and race intersect to frame violent offending [68, 69]. Miller [68] finds that Black women commit street robbery for similar reasons as their male counterparts, which helps to account for their relatively high rates compared to White females. At the same time, gender constrains the ways in which Black women plan and enact robbery, helping to account for their underrepresentation relative to their Black male counterparts. Simpson's work suggests that both structural [87] and individual-level [88] processes help account for these intersectional effects, arguing that criminogenic processes and related indicators have differential salience across subgroups disaggregated by gender and race/ethnicity. Haynie and Armstrong's [47] findings reinforce this, showing significant variation in the salience of key structural correlates for homicide offending disaggregated by gender and race jointly.

In the current study, we use administrative data to create a longitudinal birth cohort from Queensland, Australia, followed to age 25, to further refine our understanding of life course offending patterns across gender and race/ethnicity. Australia shares many features with other Western industrialized countries. As such, we would expect similar longitudinal offending patterns to those we see in studies from places like the USA, Canada, the UK, and New Zealand, where there is a history of longitudinal research, much of which has been instrumental to contemporary developmental and life course theorizing. Here we extend these efforts by examining the joint influence of gender and race/ethnicity on longitudinal offending patterns. Our work examines four key questions: (1) What is the range and patterning of longitudinal offending trajectories for individuals from an offending cohort followed into early adulthood? (2) What is the distribution of males and females across these trajectories? (3) How do individuals sort into these trajectories as a function of race/ethnicity? And (4) How do individuals sort across trajectories as a function of subgroups defined by the intersection of gender and race/ethnicity? Addressing these questions will advance our understanding of the influence of intersectionality on longitudinal offending patterns and facilitate the broader goal of testing and refining the theoretical mechanisms that might account for varied pathways within and across subgroups defined by the intersection of gender and race/ethnicity. 


\section{Life Course Studies in Australia}

While much of the work in developmental and life course criminology comes from outside of Australia, recent work with Australian samples suggests that patterns in Australia generally mirror those we see in other developed nations, reinforcing the cross-national scope of various developmental frameworks. Specifically, recent research has applied the developmental approach to examine offending trajectories among a sample of adult offenders in Western Australia [40] and among samples of juvenile offenders in Queensland [42, 61] and South Australia [65]. More importantly, and particularly relevant to the current effort, these studies assess how gender and race/ethnicity influence offending behavior over time. All four examine gender variation and Ferrante [40], Marshall [65], and Livingston et al. [61] also assess the influence of race/ethnicity by focusing on the how Indigenous status influences the distribution of life course offending patterns. Each of these Australian cohort studies also aims to provide insight into the risk factors associated with various offending patterns. Fitzgerald et al. [42] show child maltreatment to be a key feature in the lives of males and females who exhibit the most serious patterns of offending. Ferrante [40] examines a few key individual and ecological correlates and finds that similar risk and protective factors influence both high- and low-rate offending across gender and Indigenous status. Livingston et al. [61] report that economic disadvantage, but not remoteness, correlates with trajectory group membership, but do not examine whether this holds across gender or Indigenous status. These correlates are consistent with research outside the Australian context and establish the comparative utility of studies using Australian samples.

Findings from all four studies highlight the role of gender and Indigenous status in framing life course offending patterns among Australians. Coupled with broad similarities, particularly in the number and shape of trajectories across gender and Indigenous status, these studies also reinforce gender and ethnic differences evident in other countries (particularly the USA). Findings indicate that males and ethnic minorities exhibit more serious and chronic offending patterns when compared to their female and White counterparts. None, however, assesses the joint influence of gender and Indigenous status, leaving open the question of how these intersecting statuses influence age-graded offending patterns. As we discuss below, this gap reflects a broader lacuna in developmental and life course studies and is a reflection of the data constraints that define most panel studies of offenders.

\section{Gender and Life Course Offending Trajectories}

A key theoretical question for researchers examining the impact of gender on offending is "can we use the same theoretical constructions to explain female offending or do we need to derive separate theories?" ([57], p. 295). Kruttschnitt, in her summary of the literature, suggests that the formative experiences are gender neutral (poor parental relationships, low self-control, etc.) but that the emotional mediators of these experiences and the opportunities for offending may not be. From a developmental life course approach, as both gender invariant and gender variant processes unfold over time, they likely interact to generate notable differences in life course offending patterns. Although the bulk of longitudinal studies have relied on male samples [57], this is 
changing. As such, we are beginning to get a better picture of similarities and differences that characterize longitudinal patterns of offending across males and females.

A small but growing body of research has compared the shape and number of offending trajectories for males and females, as well as variation in the offenses that comprise these trajectories. Many (but not all) studies have identified both male and female chronic offenders [43]. These offenders, though typically small in number, start offending early and account for a large proportion of crime. Consistent with Moffitt's early observations $[71,73]$, these studies generally find that chronic offending is much more prevalent among male than female offenders $[6,18,20,26,33,39,56,58,61,63$, $65,70,75,79,82,90]$. Moreover, some evidence suggests females on this trajectory may onset later than males [6]. The low prevalence of female chronic offenders may explain why some studies do not even identify them at all (e.g., [26]). We see this in Australia, where Ferrante [40] identified a low- and mid-rate offending group among males and females and an additional high-rate group among males, not evident among the female offenders in her sample. It is important to assess whether this finding holds in other Australian samples since it would suggest gendered protective factors in the Australian context that may be relevant to other contexts as well.

Most of these studies look at male and female patterns separately, rather than modeling broad sample distributions and examining the comparative distribution of males and females across aggregate sample trajectories (c.f., [65]). While this is a reasonable strategy and allows for an investigation of gender differences in the shape and number of offending trajectories, there is also a methodological reason to model males and females jointly. The joint modeling strategy allows for data from both males and females to contribute to the number and type of trajectories so that we can then compare their probabilistic distributions across these shared trajectories. Moreover, if even only a handful of female offenders fit the chronic offending pattern, they would be picked up in a trajectory model that incorporates male and female group membership probabilities, while likely excluded as noise in a female only model. While such a strategy should still show females as significantly less likely to engage in the kind of high-rate chronic offending we see among males, it would allow assessment of whether there is a small but discernible group who do evidence the kind of serious offending trajectory seen among chronic male offenders.

In addition to chronic offenders, numerous studies have identified both males and females in a (typically larger) group of offenders who primarily act out during adolescence [43]. This group, according to Moffitt [72], follows a more normative pathway in which offending emerges in concert with the biological changes, shifting peer culture and new social stressors that accompany adolescence. These experiences are salient for both males and females, and not surprisingly, studies show greater gender symmetry in the prevalence of adolescent-specific offending than chronic offending $[18,20,56,61,70,75]$. Still, even among the group that only offends during adolescence, males are overrepresented and exhibit higher rates of problem behavior, especially when official offending is the marker [43]. Additionally, Fergusson and Horwood's [39] research with a New Zealand birth cohort indicates that there may be multiple types of adolescent offenders with different ages of onset and that these groups may vary across gender. We offer further evidence to help sort out how gender conditions patterns of adolescent offending, especially in relation to age of onset, 
offending duration, and offense severity. This is important because it has implications for theorizing about the comparative salience of various adolescent processes for male and female offending.

Studies also provide evidence for a low-rate offending group and indicate that this is the most common trajectory across gender [26]. At the same time, compared to males, females are particularly likely to cluster in this group [39, 40]. Focusing on convictions in a sample of offenders from the Netherlands, Block et al. [18] report that, compared to men, women are significantly more likely to be sporadic offenders with conviction rates close to 0 in adulthood ( $84 \%$ of women and $69 \%$ of men). This is not surprising given that girls and women generally exhibit less problem behavior than boys and men.

More recent studies following samples into adulthood have identified an adult onset group $[18,27]$. This work suggests that, for some, adult onset can trigger chronic offending, and for others, it appears to spur more sporadic and less serious offending $[27,93]$. Women are more likely to populate this trajectory than the chronic offender trajectory [6]. In some studies, female adult onset offenders outnumber males $[15,18$, $27,36,100]$, although this is not a uniform finding [83,93]. This is the offending group we know the least about, and because our sample follows an offending cohort into adulthood, we can help outline the key features of this group and its distribution across gender as well as race/ethnicity.

In sum, although studies are not entirely uniform in their conclusions, on balance research suggests that, among male and female offenders, there are four broad offending patterns that unfold over the life course: chronic offenders, adolescent offenders, low-rate offenders, and adult onset offenders. Chronic offenders are rare, especially among females, whereas low-rate offending is particularly characteristic of female offenders tracked over time. The life course research on females remains sparse and only a few studies follow females into adulthood. Using data from Australia, we contribute to this growing body of work by helping to establish the cross-national scope and comparativeness of findings to date and by detailing gendered offending patterns into early adulthood.

\section{Race/Ethnicity and Life Course Offending Trajectories}

Internationally, few studies have examined age-graded offending patterns disaggregated by race/ethnicity [31]. This reflects both a lack of theoretical guidance as to how race/ethnicity might influence life course offending patterns and sample size limitations that preclude disaggregation by race/ethnicity [48]. However, there is reason to believe that race/ethnicity conditions life course offending patterns in important ways [72]. Work in both the USA [46, 91] and Australia [40, 61, 65] suggests that serious offending is notably more common among minorities compared to Whites. In the USA, the literature on race/ethnicity and crime convincingly links the disadvantages that accrue to minority populations, particularly Blacks, and related structural and systemic biases, with their disproportionate involvement in offending, especially serious and chronic offending [81]. The few life course studies to examine race/ethnicity focus primarily on the experiences of Blacks, although some recent work outlines longitudinal offending patterns among samples of Hispanics [51, 63]. Studies comparing Blacks to Whites indicate that Blacks populate chronic offending trajectories at significantly higher rates than Whites $[32,64,82,101]$ and that this reflects their unique 
structural contexts and related exposure to key risk factors that both foster early onset and preclude desistance [48, 84].

In Australia, Aboriginal and Torres Strait Islanders (hereafter referred to as Indigenous Australians) represent the country's largest minority group, as well as the group with the most complex and extensive local history. In the few studies to examine life course offending patterns by Indigenous status in Australia, Indigenous offenders populate chronic trajectories at higher rates than non-Indigenous offenders [40], 61, 65]. In many ways, the criminal justice system experiences of Indigenous Australians appear to echo those of minorities in the USA and Canada, with similar minority overrepresentation in the chronic offender groups. Most notably, the patterns of Indigenous overrepresentation in the criminal justice system [9] mirror those we see among Black, Hispanic, and Native American populations in the USA [45] as well as those we see among Indigenous populations in Canada [25, 101]. Indigenous Australians are overrepresented among offenders [17, 62, 89] and although they account for approximately $3 \%$ of the population [10], they make up over $25 \%$ of the country's adult prison population [9]. In fact, their age standardized imprisonment rate is 15 times that of non-Indigenous Australians [9]. As is the case in the USA, disadvantage is at the root of this overrepresentation, although its origins are unique to the Australian historical context. Colonization, the process of European settlement and control over the colonies, and dispossession leading to the systematic undermining of established social, cultural, and economic foundations have resulted in profound problems in Indigenous communities. These include increased rates of alcohol and substance abuse, family violence, and child neglect and abuse, along with increased criminal involvement $[3,96]$. Coupled with system biases that tend to disadvantage Indigenous Australians, these processes result in increased formal intervention and related overrepresentation in the criminal justice system [29, 97]. While substantively distinct, these dynamics parallel the experiences and contemporary outcomes associated with slavery and intergenerational poverty in the shared history of African Americans. Despite overrepresentation among chronic offenders, life course offending patterns among minorities suggest that, like their White counterparts, they are still more likely to populate the less serious and more time-limited offending trajectories [24]. Work by Ferrante [40] suggests similar patterns among Indigenous offenders in Australia. Less clear, though, is the relative distribution of minorities into nonchronic offending trajectories and the correlates that account for these nonchronic patterns.

There is an obvious need for research to more fully investigate the influence of race/ethnicity on longitudinal offending patterns. A clearer picture of the influence of Indigenous status on longitudinal offending patterns is essential for understanding and addressing issues of system overrepresentation that compound the disadvantages that accrue among Indigenous populations in Australia. Moreover, given similarities in the historical and social histories of Indigenous Australians and minorities elsewhere, especially Blacks in the USA and Aboriginal populations in Canada, this work contributes to the broader body of work in race/ethnicity and life course offending patterns.

\section{Life Course Offending Patterns and the Intersection Between Gender and Race}

As we have noted, the bulk of research on life course offending patterns focuses on males. The literature on female offending patterns is growing and, although smaller, so 
too is the literature on life course offending patterns across race/ethnicity. However, we know little about how gender and race/ethnicity intersect to shape life course offending patterns. Work by White and Piquero [99] examining gender differences in life course offending patterns for a sample of African Americans suggests more similarity by gender in chronic offending among Blacks than we see in nonminority samples.

Consistent with this, Piquero and Buka [82] identified higher rates of violent offending and chronic offending among non-White (primarily Black) females than White females. Furthermore, non-White females in the sample exhibited rates of violence similar to White males, though lower than non-White males. Despite the limited evidence that speaks to the joint importance of gender and race/ethnicity, data limitations are partly to blame for the dearth of studies examining how gender and race/ethnicity intersect to shape life course offending patterns. To evaluate patterns across subgroups defined by both gender and race/ethnicity requires large samples with substantial numbers of both female and minority offenders. We are in the unique position of having a dataset that covers an entire birth cohort $(N=129,782$ individuals and 41,280 offenders) and includes enough female and Indigenous offenders to allow for an examination of the joint influence of gender and Indigenous status on life course offending patterns. As such, we are able to contribute to the emerging literature on gender and race/ethnicity intersectionality and offending, which to date focuses on qualitative or cross-sectional data, precluding any conclusions about the developmental/life course effects of intersectionality. Recent work by Bell [14] with the Philadelphia Birth Cohort shows the influence of intersectionality on offending at key developmental moments by looking at its effects on juvenile and young adult offending. She finds cumulative effects that are most acute in young adulthood. However, she does not take full advantage of the longitudinal nature of the data, effectively conducting a series of cross-sectional analyses at different developmental moments. Here we assess variation in developmental offending trajectories across subgroups defined by the intersection of gender and Indigenous status, offering a clear picture of how intersectionality affects longitudinal offending patterns.

\section{The Current Study}

Using a linked administrative longitudinal dataset from Queensland, Australia-The 83/84 Queensland Longitudinal Dataset (83/84 QLD) - the current study examines patterns of life course offending broadly and across gender and Indigenous status both separately and jointly. The 83/84 QLD contains all offending contacts with the Queensland criminal justice system between the ages of 10 and 25 years for individuals born in 1983 or $1984(N=41,280)$. The data include demographic indicators that allow us to detail offending patterns across both gender and Indigenous status. Queensland is Australia's third most populous state with a total population of 4.5 million. Indigenous Australians (which includes both Aboriginal and Torres Strait Islander peoples) make up $4.2 \%(188,954)$ of Queensland's population [9].

Using the $83 / 84$ QLD followed through to age 25, our work aims to contribute to the literature on life course offending patterns in four key ways. First, we detail life course offending patterns in an Australian context to help build the evidence base regarding cross-national similarities and differences in longitudinal offending trajectories and 
establish the broad generalizability of our findings. Second, using detailed offending data for all individuals born in 1983/1984 who have at least one court finalization, we have a large enough sample of female offenders to fully detail the comparative likelihood with which male and female offenders populate the distinct offending trajectories we identify in these data. Third, we have a large enough Indigenous sample to assess variation in the distribution of Indigenous and non-Indigenous Australians into the life course offending pathways we identify. Detailing these patterns allows us to further assess how similar patterns are in Australia compared to other countries where we have more evidence detailing longitudinal offending patterns as a function of gender and race/ethnicity. Finally, and perhaps most notably, the large dataset allows us to assess how gender and race/ethnicity jointly condition life course offending patterns, a question for which we currently lack an empirical evidence base. By detailing these gender by race/ethnicity patterns, we aim to identify salient patterns that can inform theoretical testing and refinement to account for the joint influence of gender and race/ethnicity on life course offending trajectories.

In order to address these aims, we focus on four empirical questions: (1) What is the range and patterning of longitudinal offending trajectories in an Australian birth cohort? (2) What is the distribution of males and females across these trajectories? (3) What is the distribution of Indigenous compared to non-Indigenous Australians across these trajectories? And (4) How do individuals sort across trajectories as a function of subgroups defined by the intersection of gender and Indigenous status?

\section{The Data}

The current study uses data from the 83/84 Queensland Longitudinal Database (83/84 QLD; [5]). The 83/84 QLD is a linked administrative dataset containing all contacts that individuals with a 1983 or 1984 birthdate had with the following Queensland systems: the child protection system, the youth justice system, and the adult court system. These data were linked in 2011 when cohort members were 25 or 26 years of age. The present study focuses on individual offending contacts from ages 10 (the age of criminal responsibility in Australia) to 25 years. In Queensland, individuals are considered to be a youth offender if they are aged between 10 and 16 years at the time of the offense (Youth Justice Act (QLD), 1992). Beyond this age, individuals are considered adult offenders.

Our key interest is in detailing offending patterns across gender and Indigenous status. Gender and Indigenous Australian status were recorded across all administrative datasets. Data cleaning was performed within and between the datasets to ensure that individuals were consistently assigned the same value on gender and Indigenous status. The indicators of gender and Indigenous status both had some problems with missing values and inconsistent recording. These problems are less acute with respect to gender since gender is more routinely and consistently recorded across datasets. Where possible, missing values for gender were propagated from other linked records. We excluded 97 individuals because of missing data on gender.

Similarly, some individuals had Indigenous status inconsistently recorded or missing across the administrative databases. It was not until 2003 that Queensland criminal justice agencies began routinely documenting Indigenous status. Consequently, for individuals born in 1983 or 1984, any administrative data from the Queensland 
Police Service (QPS) (youth diversion) and the adult court data collected prior to 2003 did not include Indigenous status. However, the administrative systems recording Children's Court involvement began documenting Indigenous status prior to 1993 where available, so these data do include Indigenous status. Where possible, missing values for Indigenous Status in alternate systems were propagated across the records, relying primarily on Children's Court data or more recent (post 2003) criminal justice data. In accordance with national best practice guidelines established by the Australian Institute of Health and Welfare [11], an individual was coded as an Indigenous Australian if they were recorded as such on at least one dataset. Even so, $23 \%$ of individuals in the final data set had a missing value for the variable Indigenous status. As a conservative approach, we set these cases to non-Indigenous status. This comports with the fact that even with missing data for $23 \%$ of the sample, the data indicate that $83 \%$ of Indigenous males make contact with the criminal justice system by age 25 suggesting that it is non-Indigenous Australians who are less likely to have their ethnicity recorded. We also ran all our analyses with these cases deleted from the models. The substantive patterns we observe in the data using the full sample (with these cases set to "non-Indigenous") mirror those for the models in which we deleted these cases.

In describing the longitudinal distribution of offending, we take advantage of information on the type of offending, the timing of offending, and its severity. Since we use administrative data, our focus is on official offending patterns. This conforms with other studies examining longitudinal patterns based on system contact, but it does exclude less serious problem behavior that is often the focus of studies using self-report data and that may precede system contact. As is always the case, it is important to be mindful of what we are modeling and recognize that our focus is on age-graded patterns of officially sanctioned offending behavior as a function of gender and Indigenous status. These patterns are shaped by individual behavior as well as the structural contexts in which this behavior takes place and related criminal justice system practices and responses. Any similarities and differences we report are likely a function of these micro and macro level processes and theoretical accounts of these patterns should reflect this.

In this study, offending is defined as a conviction or guilty plea/admission for an offense. Data were available for all offenses that resulted in a conviction or guilty plea for each individual between 10 and 25 years of age. We excluded minor traffic offenses, but included serious driving offenses, such as driving under the influence, dangerous driving, and driving resulting in injury. We also excluded breach offenses from the final dataset, as these offenses are typically technical breaches of administrative orders. Including these offenses would inflate the offending behavior by the cohort. One benefit of using finalizations rather than arrests is that cases of unfounded arrest drop out of the data, reducing the influence of potential police bias. Of course, we still have to be mindful of biases that might inflate Indigenous contact with the system in general and those that could influence court outcomes. However, this is a general limitation of official data and one we reflect on in the conclusions.

The offender's age at the time of offense was calculated using the earliest date available for each offense and the offender's date of birth. When available, we relied on the date of offense for these calculations. However, when the offense date was not available, the date that the offense was reported to the police was used for cautioning 
contacts and the date of lodgment was used for court appearances. We used the youngest "age at time of offense" for each offender to operationalize age at first official contact.

We describe the type of offending over the life course by determining the percentage of offenders who ever had a (a) personal offense, (b) property offense, (c) drug offense, and (d) public order offense. Offenses were classified into these four categories using the 16 categories provided by the Australian and New Zealand Standard Offence Classification (ANZSOC; [7]).

We measure seriousness of offending using three variables. First, the seriousness of each offense was computed using the Australian Bureau of Statistics' [7] hierarchical seriousness ranking, the National Offence Index (NOI). In the NOI, offenses are ranked in descending order of seriousness, from 1 = "murder" to 155 = "other miscellaneous offences." All offenses with a ranking of less than 30 were classified as "serious," which included serious violent offenses and drug trafficking. Very few offenses were classified as serious ( $4.9 \%$ of all offenses). Two additional measures of seriousness were reported: whether the individual had ever been sentenced to youth detention (aged $<17$ years) and whether the individual had ever been sentenced to adult imprisonment (between the ages of 16 and 25 years).

\section{Data Linkage}

The processes used to ensure accurate linking of the data sources, validation of the data linking processes, and de-identification of the data are described in detail elsewhere [4, 60]. The 83/84 QLD links data from three administrative databases to create individuallevel offending profiles across youth and young adulthood. First, QPS data provide details on formal police cautions for young offenders. In Queensland, children who commit minor offenses (such as shoplifting or graffiti) may be formally cautioned by police (Youth Justice Act (QLD), 1992) rather than proceeding to court. More serious offenses proceed to court for adjudication. We include data on all finalizations in the Children's Court of Queensland, which come from Queensland's Department of Communities' data. Queensland's Department of Justice and Attorney General's data provide the details for all adult court finalizations, as adults are not eligible for cautioning.

There is no unique identifier that follows individuals across the various Queensland criminal justice system agencies. Therefore, we used names (including aliases) and dates of birth to link individuals within and across the datasets [12]. We relied on "The Link King," an open source record linkage and consolidation software tool that works with SAS statistical software to conduct the data linkage and enables linkage of records across datasets, in the absence of a unique identifier. The tool employs a range of probabilistic and deterministic record linkage protocols. In particular, it uses phonetic and approximate text string matching and spelling distance algorithms to allow for subtle misspellings and typographical errors of names and dates. It also has a user interface that enables a manual review of the linking process. Because of privacy considerations, linking was done at the Queensland Office of Statistical and Economic Research (OESR) and the data were de-identified before they were released to us for research purposes. This means we could not estimate the sensitivity of the matching process [19]. However, project staff worked on the linkage with OESR and ensured that 
all records with a low probability match were manually inspected for inconsistencies and deleted where manual inspection confirmed a poor match. These cases were rare, with only about 50 cases deleted due to unreliable matching (personal communication with staff responsible for data linkage). Both the Griffith University Human Research Ethics Committee and relevant government agencies approved our use of these data for this project.

\section{The Sample}

A total of 41,280 offenders were included in this study (25.6\% female; $8.9 \%$ Indigenous Australian). These individuals were convicted of, or pled guilty to, one or more offenses between the ages of 10 and 25 years. They were responsible for 209,872 offenses $(M=5.08, \mathrm{SD}=12.31)$. Over the 15-year period, the maximum number of offenses committed by an individual was 415 offenses. However, $45 \%$ of the cohort committed only one offense. The most frequent offense category was theft and related offenses, with $26 \%$ of offenses categorized as such (Table 1). In total, the cohort is responsible for 47 homicide and related offenses.

The $83 / 84$ QLD is a population-based dataset that contains all finalized offending contacts for every individual living in Queensland at the age of 25, with a birth year of 1983 or 1984. While impressive in size and scope, these data have two relevant limitations. First, we only have individual-level data for those from this birth cohort who have had contact with the criminal justice system, and we have limited information on their experiences outside of the system. This means that we cannot account for

Table 1 Total offenses perpetrated in the 83/84 QLD cohort by the Australian and New Zealand Standard Offence Classification (ANZSOC)

\begin{tabular}{llc}
\hline ANZSOC classification $^{\text {a }}$ & Number & Percent \\
\hline Theft and related offenses & 54,515 & 25.98 \\
Public order offenses & 31,371 & 14.95 \\
Illicit drug offenses & 29,006 & 13.82 \\
Unlawful entry with intent/burglary, break and enter & 22,295 & 10.62 \\
Offenses against justice procedures, government security, and government operations & 20,010 & 9.53 \\
Property damage and environmental pollution & 15,703 & 7.48 \\
Dangerous or negligent acts endangering persons & 10,532 & 5.02 \\
Acts intended to cause injury & 9494 & 4.52 \\
Deception and related offenses & 8792 & 4.19 \\
Weapons and explosives offenses & 3153 & 1.50 \\
Miscellaneous offenses & 1959 & 0.93 \\
Robbery, extortion, and related offenses & 1272 & 0.61 \\
Sexual assault and related offenses & 1142 & 0.54 \\
Abduction and related offenses & 581 & 0.28 \\
Homicide and related offenses & 47 & 0.02 \\
Total offenses & 209,872 & 100.00 \\
\hline
\end{tabular}

${ }^{\text {a }}$ Traffic offenses were removed from the study since they are generally not considered criminal offenses 
mortality, time off the street as a result of incarceration, or migration into and out of Queensland among the cohort. In a grand sense though, these numbers are small. By age 25, aggregate mortality rates remain low for the population, with less than 1500 (of 129,782) Queenslanders born in 1983/1984 recorded as deceased by age 25. With respect to time off the street, the concern here is that we misidentify or underestimate chronic offenders who would likely offend but for their incarceration. However, as we document in the analysis, the chronic groups are the only ones to evidence relatively high rates of incarceration suggesting that the model does not misclassify these offenders as a result of time off the street. This may also reflect the fact that offenses committed within the system (e.g., assault on a prison officer) are also included in the data. Migration is trickier as we have no reliable estimates of either incoming or outgoing cohort members. Ideally, we would link the offender cohort with population registries for the 1983/1984 birth cohort, as well as criminal justice system databases from other states. Then, to estimate rates of system contact, we would divide the number of individuals who had at least one finalized contact inside or outside Queensland (the numerator), by the entire population of individuals born in 1983/1984 (the denominator; [2, 22, 53]). It is important to note though that this would still be imperfect, since it would not account for migration or mortality. Moreover, due to privacy legislation, we cannot link birth registry data to the 83/84 QLD. Instead, we rely on the best proxy available to us: publicly available census data.

Census data can provide a reasonable estimate for the denominator [22], allowing us to calculate the lifetime rate of offending for all individuals born in 1983 or 1984 and living in Queensland at the age of 25. This method of estimating lifetime prevalence rates is established practice in epidemiological and public health research [55] and addresses one common critique of offender based longitudinal data - the lack of comparative information on nonoffenders. We use these data to generate a nonoffender group as a comparative benchmark to help quantify and interpret the relative prevalence of offending within each group. Moreover, we also use 2011 Census data to generate our estimates of population contact with the criminal justice system, which helps account for migration into and out of Queensland among this cohort. In other words, since the system contacts reflect contacts for anyone living in Queensland with a birth year of 1983/1984, we base our estimates on the total number of 25-year olds in Queensland from that same birth cohort (irrespective of birthplace). Our prevalence estimates, then, are point in time estimates normed against 2011 Census data to reflect the current size and distribution of Queenslanders in this birth cohort. Linking with Census data is also illustrative when we describe gender and Indigenous subpopulation distributions since it allows us to estimate the relative proportions of each group involved in offending at all, as well as the nature and patterning of that offending.

The 2011 Census identified a total of 129,782 individuals in Queensland with birthdates in 1983 or 1984 [8]. Using system contacts in the 83/84 QLD cohort as the numerator, the lifetime rate of offending by this birth cohort was 318 per 1000 . That is, since the age of 10, 31.8 \% of 25-year-old Queenslanders had at least one offense that resulted in a contact with the criminal justice system. However, when these data are disaggregated by gender and Indigenous status, the prevalence rate of offending is not equally distributed across the demographic groups (Table 2). Specifically, Indigenous males are severely overrepresented. While they comprise $2.3 \%$ of the population, they make up $6.1 \%$ of those with criminal justice system (CJS) contacts. Moreover, they 
Table 2 Lifetime rate of contact for offending by 25-year-old Queenslanders by Indigenous status and gender

\begin{tabular}{|c|c|c|c|c|c|c|}
\hline \multirow[t]{2}{*}{ Demographic group } & \multicolumn{2}{|c|}{$\begin{array}{l}\text { Population of } \\
25 \text {-year olds } \\
(2008 / 2009)^{\mathrm{a}}\end{array}$} & \multicolumn{2}{|c|}{$\begin{array}{l}\text { 25-year olds } \\
\text { who had contact } \\
\text { with the CJS }\end{array}$} & \multirow[t]{2}{*}{$\begin{array}{l}\text { Group-based Lifetime rate } \\
\text { of offending (per 1000) }\end{array}$} & \multirow[t]{2}{*}{$\begin{array}{l}\% \text { Denographic group } \\
\text { with no CJS contact }\end{array}$} \\
\hline & $N$ & $\%$ & $N$ & $\%$ & & \\
\hline Indigenous males & 3029 & 2.3 & 2532 & 6.1 & 836 & 16.4 \\
\hline Non-Indigenous males & 62,973 & 48.5 & 28,164 & 68.2 & 447 & 55.3 \\
\hline Indigenous females & 2939 & 2.3 & 1157 & 2.8 & 394 & 60.6 \\
\hline Non-Indigenous females & 60,841 & 46.9 & 9427 & 22.8 & 155 & 84.5 \\
\hline Total & 129,782 & 100 & $41,280^{\mathrm{b}}$ & 100.0 & 318 & 68.2 \\
\hline
\end{tabular}

${ }^{\text {a }}$ Based on [7] and [80]

${ }^{\mathrm{b}}$ Ninety-seven individuals were excluded because of missing data on gender

have a lifetime offending rate of $836 / 1000$, meaning $83.6 \%$ of all Indigenous males having contact with the criminal justice system by age 25 years. Non-Indigenous females are underrepresented, with 155 per 1000 experiencing system contact by age 25 . This means that $84.5 \%$ of non-Indigenous females never have any formal contact with the criminal justice system by age 25 years. Rates of system contact for nonIndigenous males and Indigenous females fall somewhere in the middle, with $40 \%$ of Indigenous females and $45 \%$ of non-Indigenous males having at least one system contact by age 25 . In what follows, we describe how these patterns of contact unfold and vary from age 10 to age 25 both within and across groups disaggregated by gender and Indigenous status (independently and jointly).

\section{Analytic Strategy}

Following the lead of the bulk of studies that examine the patterning of offending over the life course, and across gender and race/ethnicity, we use the semiparametric group method (SPGM; [77]) with the SAS procedure "PROC TRAJ" [52] to identify the number and longitudinal distributions of offending trajectories that best represent the range of life course offending patterns among cohort members. While SPGM has its limitations (see [33]), it remains widely used and has a number of strengths relevant to the current project [78]. For one, following this analytic course allows us to compare our models to those reported in similar studies in Australia and cross-nationally. Additionally, we frame this research in the context of taxonomic models of offending patterns and aim to assess distribution across taxonomic groups as a function of gender, Indigenous status, and the intersection of the two. SPGM is particularly suited to this aim [78]. To facilitate SPGM, we calculate the total number of offenses per year for each individual in the cohort. To enable the trajectory analysis to converge, a small number of offenders with 20 or more offenses recorded in a single year $(n=630 ; 1.5 \%)$ were scaled. Most individuals in the dataset offended for short periods of time resulting in data cells with zero counts for offending. Consequently, the offending count data was distributed according to the zero-inflated Poisson distribution (ZIP) $[38,76]$. 
The SPGM does not determine the number of distinct trajectories or their shape; rather, the researcher compares models with different trajectory parameters to determine the best fitting model based on both theoretical expectations and statistical goodness of fit. To do this, we relied on an iterative process to select the final model. Prior to each analysis, we specified both the number of trajectory groups being modeled (between two and seven) and the form of these trajectories (i.e., cubic, quadratic, linear, etc.). We follow standard protocol, assessing BIC and AIC values as well as group membership probabilities to identify the best fitting model. For more specifics on model selection procedures, see Allard et al. [5].

We model the entire sample and examine gender and race/ethnicity differences in the distribution of group membership probability rather than modeling gender and race/ethnicity subgroups separately. We do this for two key reasons. First, as noted earlier, using one set of trajectories and examining differences in subgroup distributions into the various trajectories allows us to clearly compare how individuals sort across pathways as a function of gender, race/ethnicity, and their intersection. Second, given the numerous subgroups we compare by including an analysis of the intersection of gender and race/ethnicity, the number of trajectory models we would be comparing would be unwieldy, and similarities and differences across groups would be difficult to quantify. By focusing on one set of trajectories, we can evaluate, in detail, similarities and differences in how subgroups sort into the various trajectories and can make comparisons to other studies detailing the offending trajectories of various longitudinal cohorts. It is worth noting here that we did estimate separate trajectories for males and females and for Indigenous and non-Indigenous subpopulations (results available on request). Overall, the general patterns and conclusions we report here mirror those we see when we examine distributions disaggregated by gender or Indigenous status. ${ }^{1}$

\section{Results}

\section{Longitudinal Offending Trajectories in an Australian Birth Cohort}

Using SPGM, we identified a model with five distinct offending trajectories as the optimal model to describe this population. In calculating offending trajectories, we exclude cohort members with no criminal justice contacts (nonoffenders) for both empirical and methodological reasons. Empirically, we only have data for cohort members with criminal justice system contacts, which means that we cannot model those who do not have any system contact. Methodologically, even if we did have data on those with no criminal justice system contacts, including them would add nothing to the model

\footnotetext{
${ }^{1}$ We explored whether there were differences in the number, shape, and distribution of latent trajectories using the SPGM approach, depending on whether we analyzed the data as an entire group (dominated by nonIndigenous males-NIM), or if we analyzed the data for the four individual subgroups, namely NIM, IM, NIF, and IF. The underlying latent categories were relatively consistent across models, with differences observed in the relative proportions that fell within each trajectory group, the level of chronicity that defined the categories, and the slight adjustment in the age at which offending onset or desisted for each group. On balance, each of the four individual models was relatively consistent with the overall sample model and generated similar conclusions with respect to the distribution of offenders into various offending trajectories. The main exception was that for the model of NIM only, there was an additional distinct adult onset trajectory not evident in the other subgroups.
} 
beyond generating a flat, nonoffender trajectory, and by including them, we run the risk that our low-level offenders get pulled into the nonoffender group. This would make it particularly difficult to discern how many females are actually low-level offenders as opposed to nonoffenders. So, focusing on those with one or more conviction we document five emergent groups, which we describe as adolescent onset-low offending, adult onset - low offending, adolescent onset - moderate offending, early onset - chronic offending, and adolescent onset - chronic offending (Fig. 1 and Table 3).

The population sorts into groups consistent with our expectations given the broad life course offending literature. As well, the frequency of offending within these groups conforms to expectations. Using census-based population estimates as our base, $68.2 \%$ of the 83/84 cohort are nonoffenders. The largest offender group is the adult onset-low offending group, which represents over half of the offenders and $16.9 \%$ of the total population. Although this group would likely be smaller if we used self-report rather than official data (see $[67,74]$ ), the existence of this group is consistent with the growing literature following samples and cohorts into adulthood (e.g., [18, 33, 56]). On average, individuals in this group had their first system contact at age 21 and, followed to age 25, averaged two offenses each, the bulk of which are of a less serious nature (primarily public order offenses). The other large group also follows a low-level offending trajectory, but one that onsets a bit earlier: the adolescent onset-low offending group. This group represents $9.8 \%$ of the population cohort and $30.7 \%$ of the offenders. Their offending is limited, averaging two offenses each and, overall, not very serious, with the bulk of their offenses being property crimes. Almost none of the individuals in these groups have ever experienced detention or imprisonment.

By contrast to these larger groups, the smallest group is the early onset-chronic offending group, which represents $1 \%$ of the total population and $3 \%$ of the offender group. Still, like early onset chronics in other samples, this group exhibits the greatest number of offenses, averaging close to 46 offenses each, and the most diverse and serious offending distribution as well. This group, though, looks a lot like the adolescent onset - chronic offending group, whose first contact with the system occurred at age 17.5, but who also exhibit a diverse and serious offending repertoire. This group

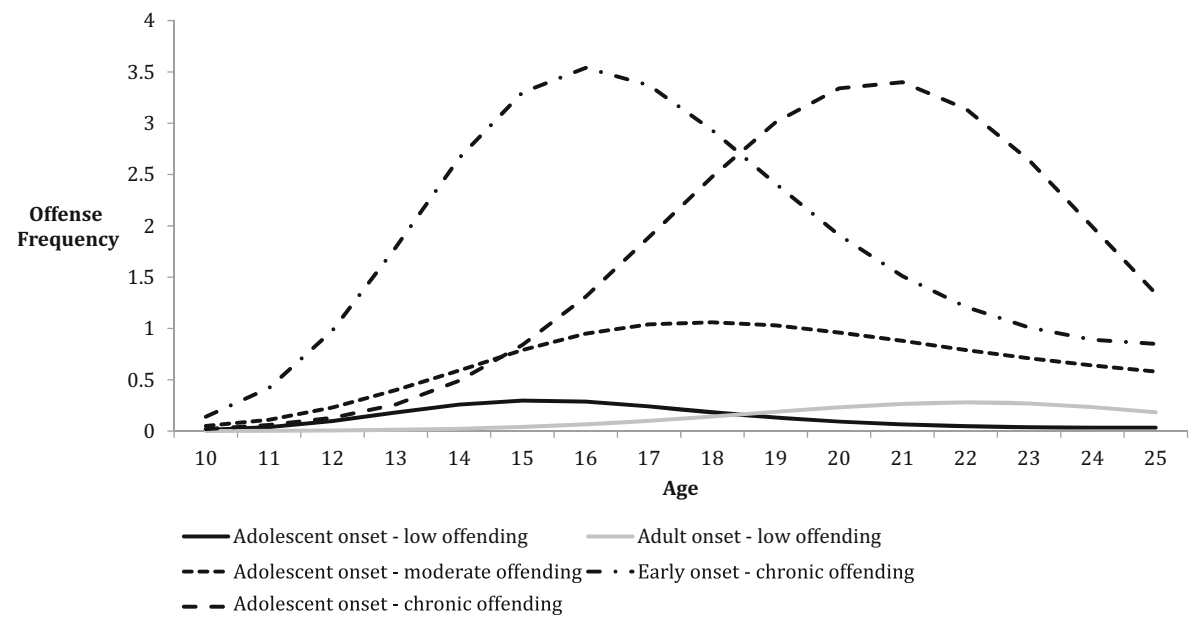

Fig. 1 Five group offending trajectory solution $(N=41,280)$ 


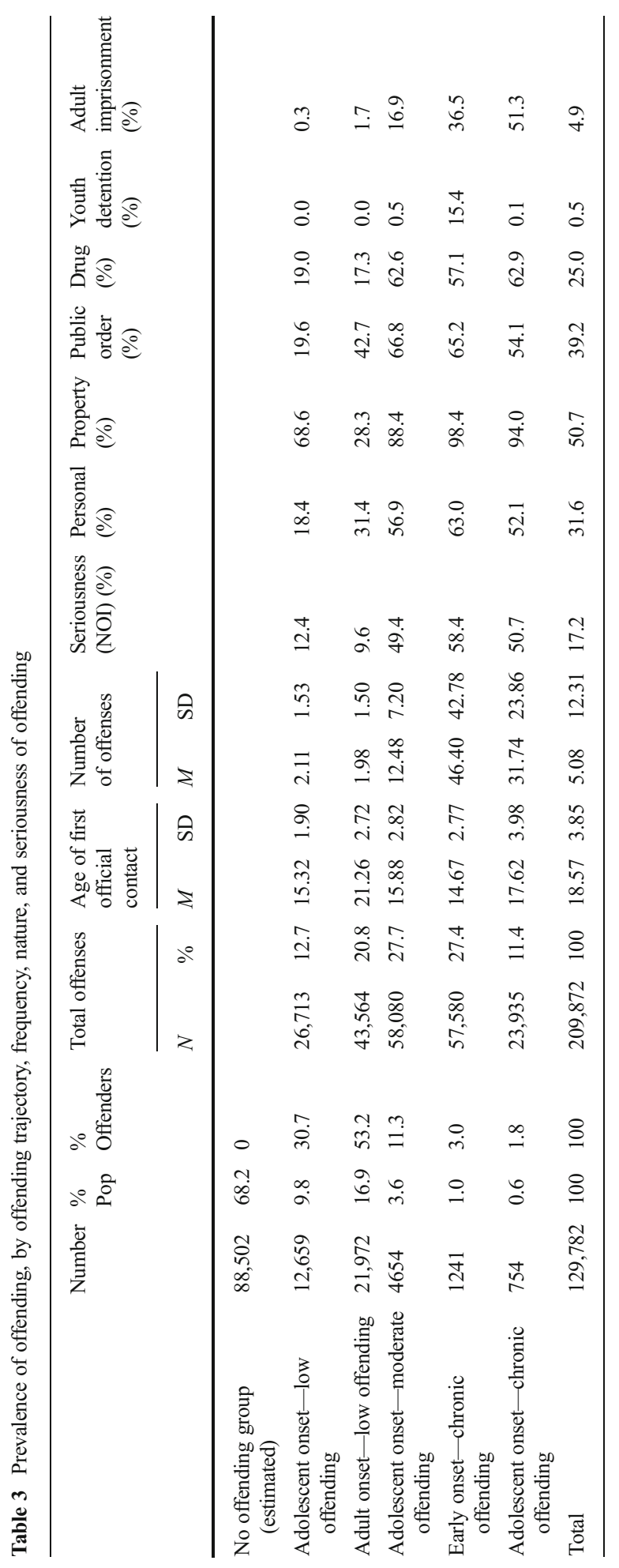


too is predictably small ( $0.6 \%$ of the population and $1.8 \%$ of the offender group). For these two groups, incarceration is a common experience. In the adolescent onset group, over half have been imprisoned, and in the early onset group, $15.4 \%$ were in juvenile detention and $36.5 \%$ have been in adult prisons. In between the two low-rate groups and the two high-rate serious offender groups is the adolescent onset-moderate offending group. This group makes up $3.6 \%$ of the estimated total cohort and $11.3 \%$ of the offenders. Individuals in this group average 13 offenses covering a relatively serious and diverse range, with $16.9 \%$ of them experiencing adult imprisonment at some point.

\section{Gender and Life Course Offending Patterns}

Having detailed the offending groups in the population, the next question we explore is how males and females are distributed across these groups and the non-offender group estimated from census data (Table 4). As we would anticipate, chi-square analysis indicates that males and females are not equally represented across the six groups $\left(\chi^{2}\right.$ $(5, N=129,782)=14,297.01, p<0.001$, Cramer's $V=0.33)$. This difference is attributable to the significantly lower likelihood of offending among females as well as their less serious involvement as offenders. Followed to age 25 , males in the cohort are significantly more likely to have engaged in the kinds of offending behaviors that trigger system involvement. Only $16.6 \%$ of females compared to $46.5 \%$ of males had contact with the criminal justice system sometime between the ages of 10 and 25 (Table 4). Further, while females, like males, can be classified into all five offending groups, they are significantly less likely to populate the moderate and chronic offending groups.

Consistent with gender distributions evident in other longitudinal samples followed into adulthood both in Australia and cross-nationally, females are most likely to populate low frequency offending trajectories characterized by either adolescent or

Table 4 Rates of offending by groups of offenders: gender

\begin{tabular}{|c|c|c|c|c|c|c|c|}
\hline & \multicolumn{3}{|l|}{ Males } & \multicolumn{3}{|l|}{ Females } & \multirow{2}{*}{$\begin{array}{l}\text { Ratio } \\
\text { Male:female }\end{array}$} \\
\hline & $\begin{array}{l}N(\% \text { of } \\
\text { offenders })\end{array}$ & $\begin{array}{l}\text { Rate }^{\mathrm{a}} \\
\text { per } \\
1000\end{array}$ & $\begin{array}{l}\text { Adj } \\
\text { Std } \\
\text { resid }\end{array}$ & $\begin{array}{l}N(\% \text { of } \\
\text { offenders })\end{array}$ & $\begin{array}{l}\text { Rate }^{a} \\
\text { per } \\
1000\end{array}$ & $\begin{array}{l}\text { Adj } \\
\text { Std } \\
\text { resid }\end{array}$ & \\
\hline No offending & 35,306 (NA) & 535 & -115.7 & 53,196 (NA) & 834 & 115.7 & $0.6: 1$ \\
\hline $\begin{array}{l}\text { Adolescent peaking-low } \\
\text { offending }\end{array}$ & $8008(26.1)$ & 121 & 29.4 & $4651(43.9)$ & 73 & -29.4 & $1.7: 1$ \\
\hline Adult onset—low offending & $17,325(56.4)$ & 263 & 91.1 & $4647(43.9)$ & 73 & -91.1 & $3.6: 1$ \\
\hline $\begin{array}{l}\text { Adolescent onset-moderate } \\
\text { offending }\end{array}$ & $3800(12.4)$ & 57 & 42.8 & $854(8.1)$ & 13 & -42.8 & $4.3: 1$ \\
\hline Early onset—chronic offending & $991(3.2)$ & 15 & 20.5 & $250(2.4)$ & 4 & -20.5 & $3.8: 1$ \\
\hline $\begin{array}{l}\text { Adolescent onset-chronic } \\
\text { offending }\end{array}$ & $572(1.9)$ & 9 & 13.8 & $182(1.7)$ & 3 & -13.8 & $3.0: 1$ \\
\hline $\begin{array}{l}\text { Total Queensland population } \\
\text { 25-year olds }\end{array}$ & \multicolumn{3}{|l|}{66,002} & \multicolumn{4}{|l|}{63,780} \\
\hline
\end{tabular}

a 2011 Census figures [7] 
adult onset. Overall, $14.6 \%$ of the total female population and $87.8 \%$ of the female offenders populate one of the two low offending trajectories. Of course, males too are most likely to populate these low offending trajectories $(38.4 \%$ of the male population and $82.5 \%$ of the male offenders). Female offenders are evenly split among these two groups $(43.9 \%$ of female offenders in each group), while male offenders are much more likely to fall into the adult onset - low offending group (56.4 vs. $26.1 \%$ ). This is notable because other studies report more evidence of adult onset among females compared to males $[15,18,27,36]$. But while $2 \%$ of the female population falls into one of the three more serious and chronic trajectories, $8.1 \%$ of the male population is represented on one of these three trajectories. In other words, males are four times more likely to populate serious and chronic offending trajectories. That said, when we restrict our examination to the male and female offenders, rather than the entire birth cohort, the percentage of male and female offenders in each of these more serious offending groups is fairly similar. The key point from this gender comparison is that, overall, females are much less likely to have contact with the criminal justice system at any point in their youth and early adulthood, but among offenders, distributions into offending groups are not wildly different by gender, especially where the more serious offending groups are concerned.

\section{Indigenous Status and Life Course Offending Patterns}

As is the case across males and females, Indigenous and non-Indigenous Australians are not equally represented across the six trajectory groups $\left(\chi^{2}(5, N=129,782)=7807.04\right.$, $p<0.001$, Cramer's $V=0.24$ ) (Table 5). On the whole, Indigenous Australians are significantly less likely to populate the nonoffender group compared to nonIndigenous Australians (38.2 vs. $69.6 \%$ ). Interestingly, non-Indigenous and Indigenous Australians were equally likely to be classified into the adolescent onsetlow offending group (0.9:1). However, this is based on population prevalence rates. If we look just at the offenders, $32.1 \%$ of the non-Indigenous Australians fall into this group, compared to only $14.9 \%$ of the Indigenous offenders. The non-Indigenous offenders are also more likely to populate the adult onset-low offending group (54.5 compared to $39.8 \%$ ), though focusing on population-based rates, Indigenous Australians populate this group at a higher rate than non-Indigenous Australians. Once we focus on the more serious trajectory groups, Indigenous Australians represent a larger proportion of these groups whether we examine population-based rates, or just focus on the distribution of offenders. This is particularly notable among the early onset - chronic offending group where the ratio of Indigenous to non-Indigenous Australians is the highest at 11.3:1. These results indicate that not only are Indigenous Australians more likely to offend, but when they do offend, they exhibit more chronic and serious offending patterns. This mirrors what we know about the relation between race/ethnicity and offending over the life course in US samples, particularly those focusing on differences between African Americans and Whites [32, 82, 101].

\section{Life Course Offending Patterns as a Function of Gender and Race/Ethnicity}

Our analyses, so far, generally conform to expectations, mirroring what we know about life course patterns of offending across gender and race/ethnicity from other 


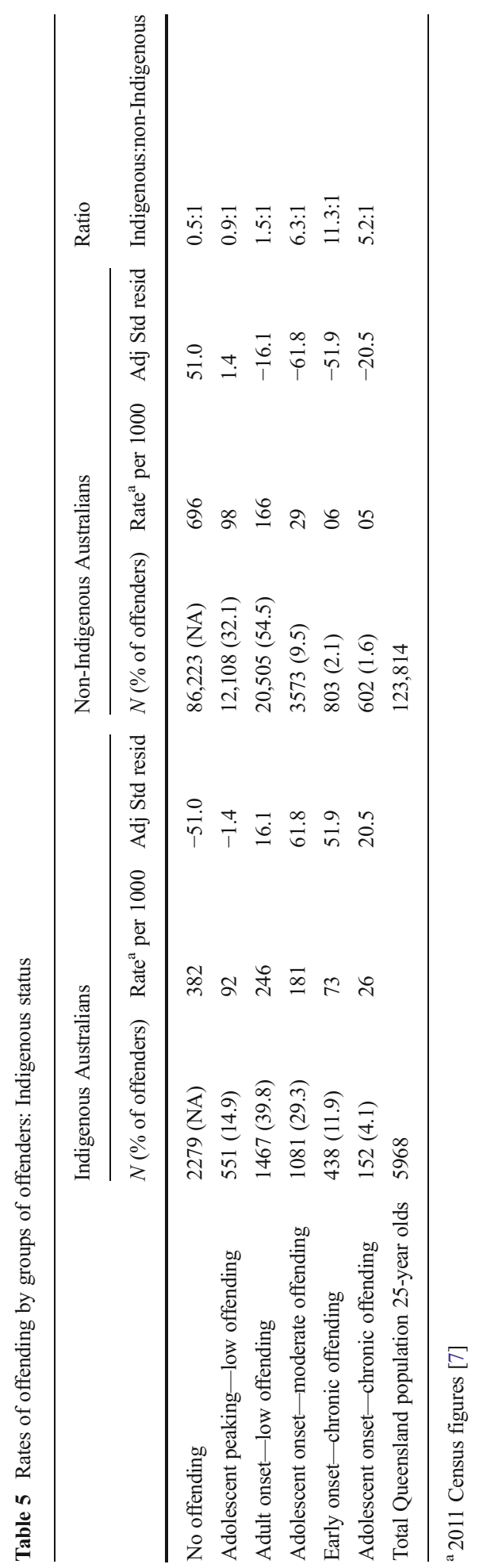


longitudinal studies. We know much less about how gender interacts with race/ethnicity. It is unclear, for example, if minority women are more strongly impacted by the gendered mechanisms that limit offending and system contact among females or by the various structural and individual-level processes that promote offending and system contact among minorities. And while evidence consistently shows higher involvement in crime among minorities, particularly males, it is not clear whether this pattern would be replicated among Indigenous Australians. To shed some light on these questions, we conduct a series of chi-square analyses that assess the interaction between gender and Indigenous status for each offending group (Table 6). Focusing first on the group with no system contacts, there is a significant interaction between gender and Indigenous status. Indigenous males have the lowest rate of nonoffending by a substantial margin. Only $16.4 \%$ of the Indigenous males fall into this group. Comparatively, $84.5 \%$ of non-Indigenous females comprise this group. In the middle are the non-Indigenous males $(55.3 \%)$ and the Indigenous females $(60.6 \%)$. In other words, Indigenous status puts females at greater risk of system contact than their nonIndigenous female counterparts. Moreover, while males are uniformly more at risk of system contact than females, this risk is exaggerated among Indigenous males.

Focusing on the offender groups, we find no interaction between gender and Indigenous status when we examine the two chronic offender groups. Here Indigenous status is the primary driver of differences, with both Indigenous males and Indigenous females overrepresented in these groups. The difference across race/ethnicity is striking here, with $15.8 \%$ of Indigenous males and $3.9 \%$ of Indigenous females fitting a chronic trajectory. This compares to $1.7 \%$ of nonIndigenous males and just $0.5 \%$ of non-Indigenous females. Given the seriousness and frequency of the offending among these two groups and the high rate of imprisonment, these rates conform to the disproportionate contacts evident among Indigenous males and females in adult prisons [9] and youth detention [12]. On the other end of the spectrum, when we examine the adolescent onset-low offending group, there is similarly no evidence of an interaction, but here gender, rather than race/ethnicity, is the driving influence. Males are more likely than females to be classified as adolescent onset-low offending regardless of Indigenous status.

We do see evidence that the intersection of gender and Indigenous status influences offending patterns among two offender groups: the adolescent onset-moderate offending group and the adult onset-low offending group. Indigenous males are the most likely to populate these trajectories and non-Indigenous females the least likely. Indigenous females and non-Indigenous males fall in the middle. In fact, Indigenous females exhibit higher rates of adolescent onset-moderate offending than nonIndigenous males ( 8.8 vs. $4.7 \%$ ) but are significantly less likely to populate this trajectory than Indigenous males $(27.1 \%)$. For the adult onset-low offending group, males have higher rates than females, but with $19.3 \%$ of Indigenous females populating this group, they look more comparable to non-Indigenous males $(26.1 \%)$ than nonIndigenous females (6.7\%). It is notable that, among males, Indigenous status is largely immaterial to adult onset, while among females, it is a central determinant. It appears that, while non-Indigenous females experience a degree of protection against the snares that can complicate adult transitions, males and Indigenous females are all similarly vulnerable to these snares. 


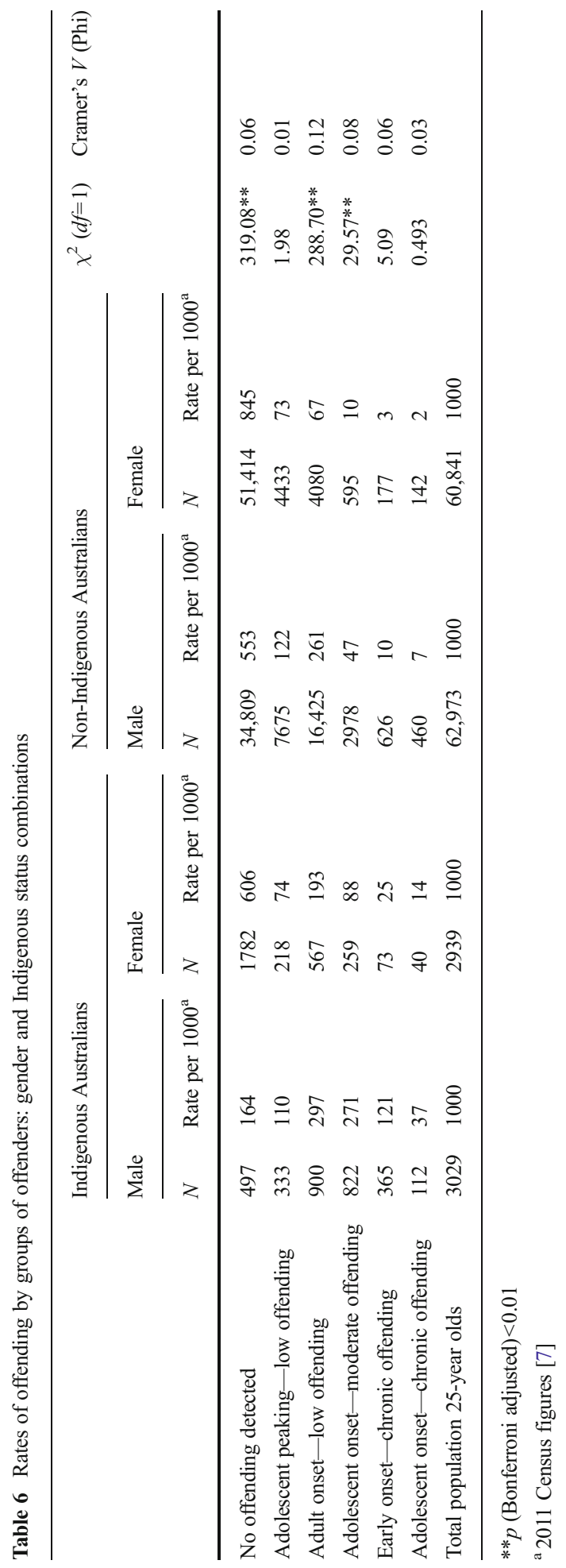


Overall, it is clear that a focus on either gender or Indigenous status alone hides notable differences across groups defined by the combined statuses. Indigenous males exhibit the most significant involvement in offending through adolescence and early adulthood. However, Indigenous females are also overrepresented in offender groups compared to their non-Indigenous counterparts. In many instances, their offending trajectories mirror those of non-Indigenous males more closely than those of either Indigenous males or non-Indigenous females. Indeed, Indigenous females are more likely to populate the adolescent onset-moderate offending group and the two chronic offender groups than non-Indigenous males.

\section{Discussion}

Our primary aim here was to detail the life course patterns of offending in a cohort of offenders born in 1983/1984 and followed from ages 10 to 25. We focus analyses on the comparative likelihood with which individuals sort into various offending pathways as a function of both gender and Indigenous status independently and jointly. We now turn to a summary of the findings, highlighting a number of important takeaway points that can inform efforts to understand how gender and race/ethnicity frame offending pathways.

To begin, our data suggest that longitudinal patterns of offending and system contact in Australia are similar to those documented elsewhere, highlighting the generalizability of these data. As we would expect, our analyses highlight a large group of individuals who never have contact with the criminal justice system. However, among those who do, patterns are not uniform. Our data suggest five prominent offending trajectories. Most offenders in our sample exhibit low-level offending that is not very serious in nature. For these individuals, system contact is infrequent and usually first occurs in adolescence or early adulthood. The more troublesome patterns are the more serious and chronic offender pathways, marked by frequent system contact for a diverse range of offenses. As is the case cross-nationally, these groups are comparatively smaller, but account for the vast majority of offenses documented in the data. Aside from a small (1.8\% of offenders) early onset chronic group, we also see two groups of frequent offenders whose first contact with the system is in adolescence, but who still accumulate a large number of officially recorded offenses by age 25 . For the comparatively moderate group, whose first system contact is at age 16, they average 13 offenses by age 25 . The adolescent onset chronic group onsets a year later (age 18), but averages 32 offenses by age 25 . Together, these three groups make up $5.4 \%$ of the birth cohort and $16.1 \%$ of the offenders in the cohort, but account for $66.5 \%$ of all offenses committed by the cohort. Focusing on system contact, our data suggest that most high-rate offenders do not engage with the criminal justice system until well into adolescence.

Our examination of the comparative likelihood of group membership across gender and race/ethnicity gives us some insight into the key dynamics that theoretical accounts of life course offending need to account for. Although not surprising given what we have seen in Australian studies to date and studies in other Western countries, gender and race/ethnicity do condition life course offending patterns in notable ways. While nonoffenders are a large proportion of the full birth cohort $(68.2 \%)$, this group is most 
pronounced among non-Indigenous females $(84.5 \%)$ and smallest among Indigenous males $(16.4 \%)$, suggesting important intersections between gender and race/ethnicity that exaggerate the risk of system contact among the Indigenous males. This is further emphasized by the finding that members of this same group, Indigenous males, exhibit the highest likelihood of membership in all three of the most chronic and serious offending pathways (42.9\% combined). These groups not only exhibit the most diverse, frequent, and serious offending patterns, but they are also the most likely to experience bouts of youth and adult imprisonment. We also find that Indigenous status, more so than gender, influences membership in these more serious trajectories, making Indigenous females similarly vulnerable to serious chronic offending in ways their nonIndigenous counterparts, both male and female, are not. While $12.7 \%$ of Indigenous females are likely to populate one of these three serious offenders groups, only $6.4 \%$ of non-Indigenous males and $1.5 \%$ of non-Indigenous females are likely to populate any one of these three groups. This mirrors what we know about the influence of race/ethnicity on longitudinal offending patterns from US studies documenting the offending pathways of Blacks and Hispanics [51, 63, 82, 101].

Clearly, the key features of Indigenous disadvantage are central to the mechanisms that explain the offending behavior of individuals likely to populate these serious, chronic trajectories. Literature on Indigenous disadvantage is important here. More Indigenous children than non-Indigenous children are identified as having a low birth weight (10 compared to $4.6 \%$; [54]), and teen mothers account for $18 \%$ of Indigenous births, compared to $3 \%$ for non-Indigenous births [92]. There is evidence of high levels of fetal alcohol syndrome and fetal alcohol spectrum disorder in Indigenous communities [21]. Within the child protection system, Indigenous youth are seven times more likely than non-Indigenous children to be the subject of a substantiated report of child maltreatment [16]. Indigenous children are also at greater risk of the intergenerational affects of parental imprisonment given that they are four times more likely to experience paternal imprisonment by age 18 than non-Indigenous children [30]. Furthermore, Ferrante et al. [41] identified that Indigenous women in rural and remote Western Australia were 45 times more likely to be a victim of domestic violence than nonIndigenous women. All of these influences have been identified as risk factors for offending in previous research, and while they cluster in Indigenous contexts, they are hardly unique to those contexts and likely affect non-indigenous offenders on these pathways as well [35].

As instrumental as Indigenous status is for the risk of long-term serious offending, our analyses suggest that we cannot ignore gender or its intersection with Indigenous status. Among those who follow a pattern of adolescent onset with low-rate offending, gender is the primary driver and Indigenous females show group membership probabilities most consistent with those of non-Indigenous females. The same is true among males. This suggests that, in adolescence, the social and contextual dynamics that fuel the sporadic, experimental offending that characterizes adolescent limited offending [1, $71,75]$ vary by gender but not by Indigenous status. In other words, unlike the highrisk chronic groups where Indigenous status introduces unique risks, less serious Indigenous and non-Indigenous offenders may respond similarly to the gendered developmental mechanisms that trigger experimental offending in adolescence.

By contrast, gender and Indigenous status interact to influence the likelihood of membership in three groups. This is important, since previous studies have not 
examined this interaction. First, looking at the nonoffenders, the joint influence of gender and Indigenous status plays prominently, with Indigenous females and nonIndigenous males exhibiting similar likelihoods of membership in this group, while Indigenous males are far less likely and non-Indigenous females are far more likely to be nonoffenders. This suggests that Indigenous status trumps some of the protections from offending and system contact that gender introduces for females. Gender and Indigenous status also interact to influence the distribution of offenders into the offending group that evidences moderate levels of offending beginning in adolescence as well as the group that onset in adulthood. Focusing on those who exhibit moderate offending starting in adolescence, a large proportion of Indigenous males fit this pattern $(27.1 \%)$ and very few non-Indigenous females $(1 \%)$. Non-Indigenous males are also less likely than Indigenous females to fit this pattern (4.7 vs. $8.8 \%$ ). In this instance, gender protects Indigenous females more so than their male counterparts, but their Indigenous status still places them at greater risk for serious problems in adolescence than is the case for non-Indigenous youth. This may reflect over policing of Indigenous communities, school disengagement among Indigenous youth, or other structural and cultural dynamics that are both gendered and differentially affect Indigenous and nonIndigenous youth.

Where official onset commences in adulthood, a group we know little about, we again see a prominent gender by Indigenous status interaction. Indigenous females are far more likely to populate this group than their non-Indigenous counterparts and more closely resemble non-Indigenous males. This suggests that the transition to adulthood is rougher for Indigenous females than is the case for non-Indigenous females. Marriage and stable families, careers or stable jobs, and the economic and social security that comes with these may be harder for Indigenous females to secure. As such, even if they successfully navigate adolescence, the challenges of early adulthood, particularly in economically depressed contexts, can prove daunting [95]. This is consistent with accounts of adult onset arising out of Farrington's Cambridge data [37, 67, 102], which highlight the role of life course exposure to disadvantage in adult onset pathways. In other words, in much the same way the transition to adulthood might trigger desistance when the key elements of successful transitions are in place, they might trigger onset where individuals on the path to successful adulthood find the transition difficult to manage. Males, irrespective of Indigenous status, are also notably more vulnerable to the snares that can complicate transitions to adulthood than are non-Indigenous females. In fact, among males, Indigenous status does not introduce additional risks for the transition to adulthood in the same way it does for females.

More generally, it is notable that, in these data, adult onset is more common among males than females. Other studies outside of the Australian context have found females to be particularly at risk for adult onset relative to males (e.g., [6, 15, 18, 27, 90]). It may be that the welfare context in Australia helps females, especially non-Indigenous ones, successfully navigate the transition to adulthood in ways that are different from other contexts. In the USA in particular, women who experience snares in the transition to adulthood may have fewer safety nets to effectively cope with these snares. It may also be the case that, for Australian males, needing or accessing these resources, even where they are available, may challenge masculine identities in ways that promote criminal coping in the transition to adulthood. As new research begins to explore the dynamics of adult onset offending and develop theoretical accounts that can explain 
this pattern, the role of social and structural context will clearly be important as will the intersecting influences of race/ethnicity and gender.

Of course, with self-report data, we might see signs of problem behavior earlier [67]. Even so, for this group, criminal justice system contact first occurs in adulthood. Notably, for this group, these adult system contacts are in response to a unique set of behaviors compared to other offending groups, which indicates a unique and important dynamic. Specifically, their offenses are not generally serious and primarily fall into the "offense against public order" category. We suggest that theoretical efforts to account for this emergent group need to pay attention to the notable differences in the character of the offending this group exhibits and the unique ways that gender and race/ethnicity seem to jointly shape the behavior of those most likely to populate this group. More broadly, theory and research needs to pay attention to these intersectional processes and how they influence life course offending patterns.

As always, this study has a number of limitations. The key limitation is the use of official (adjudicated) data. These data are left censored since, in Australia, children cannot be held criminally responsible before the age of 10 years. Consequently, early first contact behavior prior to the age of 10 years is not available for analyses. Additionally, only offending that comes to the attention of the criminal justice system and is adjudicated is included in the analyses. This may mean that those offenders classified as adolescent or adult onset may actually onset earlier with less serious problem behavior or undetected offending. However, these data do give an accurate picture of individuals who come to the attention of the criminal justice system over their life course.

The scope of our analyses is also limited by the quality and nature of the data collected by the various agencies. Indigenous status and gender were not always consistently reported within and across administrative datasets, and in some instances, these demographic variables were missing. With respect to gender, in most instances we could resolve disparities across datasets, but in some instances $(N=97)$, we had to delete cases with missing data on gender. With respect to inconsistencies in coding Indigenous status across datasets, we followed the best practice principles of data linkage, such that individuals identified as Indigenous in any database were coded as Indigenous and any with missing data on Indigenous status from all sources were coded as non-Indigenous. The final numbers are generally consistent with population numbers and with evidence of Indigenous overrepresentation in the criminal justice system.

In addition, no information was available on migration into the dataset or attrition from the dataset. This impacts our ability to correctly track an individual's offending pathway across the life course and may also create a numerator/denominator bias in estimations of lifetime prevalence rates. Queensland experiences high levels of migration from other Australian states and overseas. In 1993 and 1994, there were almost 93,000 10-year olds in Queensland and by 2008/2009 there were 130,000 25-year olds in Queensland, an increase of nearly $40 \%$ over the 15 years of data collection [80]. It is this latter figure that we use as our denominator, since it accounts for the influx of individuals born in 1983/1984 who may get caught up in the criminal justice system. Finally, few risk factors associated with chronic and adolescent offending are available in the dataset to investigate which factors are associated with different offending pathways. This would require links to other administrative datasets (e.g., health services data, child welfare data, education data, employment data) and more complicated 
linking methods with tighter privacy and security restrictions. Smaller longitudinal studies using self-report methods can also fill in some of these gaps and help articulate how well existing theories account for the life course offending patterns we see among Australian cohorts.

While there are limitations with the use of official data, these data also have substantial strengths. Data are provided on an entire cohort of offenders enabling us to examine rare offending (serious female offending), the offending of a marginalized racial minority group, and the interaction between gender and race/ethnicity. It is very difficult to obtain representative samples of Indigenous Australians as they only represent $3 \%$ of the Australian population and less than a third live in urban areas. It is even more difficult to obtain samples that can be disaggregated across both gender and Indigenous status.

\section{Conclusions}

As a whole, our findings suggest that patterns in Australia mirror those we see in other countries, but also introduce the importance of examining the joint influence of gender and race/ethnicity on these patterns. To begin, our results highlight the idea that gender conditions life course offending pathways in important ways. The more serious and stable the offending pathway, the more significant the gender gap in the likelihood of group membership. Theoretical accounts of life course offending need to pay attention to the way in which gender influences the relevant individual, social, and contextual dynamics that frame risk and protection and shape broad behavioral repertoires. While life course developmental models invoke mechanisms like early temperament, child maltreatment, family and peer dynamics, and exposure to disadvantage that may be gendered, they rarely outline the specific ways in which gender might be operant and its implications for the differential distribution of males and females into offending pathways. This is important not just for our understanding of developmental pathways in Australia, but cross-nationally [57].

Also echoing the findings from prior studies with Australian cohorts, Indigenous status shapes life course offending patterns. That both male and female Indigenous Australians populate serious and chronic offending trajectories at rates higher than nonIndigenous males and females suggests that the disadvantages that accrue to Indigenous Australians appear to push them into the system in unique ways. While individual differences that accrue in disadvantaged contexts are likely part of the explanation, it seems unwise to ignore cultural and structural differences that might also come into play. For instance, personal and vicarious life course experiences with the criminal justice system are abundant in Indigenous communities, and these experiences likely have important implications for life course offending patterns. Parental offending and imprisonment, family disruption, distrust of the system, and related processes all help explain the intergenerational cycle of system involvement that tends to characterize backgrounds of Indigenous offenders, both male and female [29, 96, 97]. Explanations of life course offending patterns in Australia cannot ignore these dynamics. Indeed, there is evidence to suggest that these dynamics are not unique to Indigenous Australians, but affect the life course offending patterns of minorities in other countries as well $[48,84]$. 
Finally, our analyses clearly document that theory and research in developmental and life course criminology should pay more attention to the ways that race/ethnicity intersect with gender to frame the life course experiences of offenders (e.g., [72]). In adolescence, for instance, race/ethnicity appears to play a central role in the processes that generate and promote more serious and protracted offending among females. In addition, the overall risk for offending is higher for males than females, but race/ethnicity is also important here since it appears to exaggerate the risk of criminal involvement and system contact for both males and females.

Moving forward, developmental and life course models need to highlight not just the operant developmental dynamics across key life stages or the relevant, age-graded risk and protective factors at play, but also the ways in which gender and race/ethnicity condition these processes both independently and jointly.

\section{References}

1. Agnew, R. (2003). An integrated theory of the adolescent peak in offending. Youth \& Society, 34, 263299.

2. Ajwani, S., Blakely, T., Robson, B., Atkinson, J., \& Kiro, C. (2003). Unlocking the numeratordenominator bias III: adjustment rations by ethnicity for 1981-1999 mortality data. The New Zealand Census-Mortality Study. The New Zealand Medical Journal, 116, 1175.

3. Allard, T. (2010). Understanding and preventing Indigenous offending. Indigenous Justice Clearinghouse, National Justice CEOs Group.

4. Allard, T., Stewart, A., Chrzanowski, A., Ogilvie, J., Birks, D., \& Little, S. (2010). The use and impact of police diversion for reducing Indigenous over-representation. Final Report to the Criminological Research Council.

5. Allard, T., Stewart, A., Smith, C., Dennison, S., Chrzanowski, C., \& Thompson, C. (2014). The monetary cost of offender trajectories: findings from Queensland Australia. Australian and New Zealand Journal of Criminology, 47, 81-101.

6. Andersson, F., Levander, S., \& Levander, M. T. (2012). A life-course perspective on girls' criminality. In A.-K. Andershed (Ed.), Girls at risk: Swedish longitudinal research on adjustment. New York: Springer.

7. Australian Bureau of Statistics (2011). Australian and New Zealand Standard Offence Classification (ANZSOC) (3rd edition). Catalogue no: 1234.0. Canberra: Commonwealth of Australia.

8. Australian Bureau of Statistics (2012). Year Book Australia 2012. Catalogue no: 1301 Canberra: Commonwealth of Australia.

9. Australian Bureau of Statistics (2013). Prisoners in Australia. Catalogue no: 4517.0. Canberra: Commonwealth of Australia.

10. Australian Bureau of Statistics (2014). Estimates and Projections, Aboriginal and Torres Strait Islander Australians. Catalogue no: 3238.0. Canberra: Commonwealth of Australia.

11. Australian Institute of Health and Welfare and Australian Bureau of Statistics (2012). National best practice guidelines for data linkage activities relating to Aboriginal and Torres Strait Islander People. AIHW Catalogue no: 74. Canberra: AIHW.

12. Australian Institute of Health and Welfare (2013). Youth justice in Australia 2011-12: an overview. AIHW bulletin 115. Catalogue no: AUS 170. Canberra: AIHW.

13. Baskin, D. R., \& Sommers, I. B. (1998). Casualties of community disorder: women's careers in violent crime. Boulder: Westview.

14. Bell, K. E. (2013). Young adult offending: intersectionality of gender and race. Critical Criminology, 21, 103-121.

15. Bergman, L. R., \& Andershed, A.-K. (2009). Predictors and outcomes of persistent or age-limited registered criminal behavior: a 30-year longitudinal study of a Swedish urban population. Aggressive Behavior, 35, 164-178.

16. Berlyn, C. Bromfield, L. \& Lamont, A. (2011). Child protection and Aboriginal and Torres Strait Islander children. National Child Protection Clearing House Resource Sheet. Australian Institute of Family Studies: Commonwealth of Australia. http://www.aifs.gov.au/nch/pubs/sheets/rs10/rs10.pdf 
17. Blagg, H., Morgan, N., Cunneen C., \& Ferrante, A. (2005). Systemic racism as a factor in the overrepresentation of Aboriginal people in the Victorian criminal justice system. Report to the Equal Opportunity Commission of Victoria.

18. Block, C. R., Blokland, A. A. J., van der Werff, C., van Os, R., \& Nieuwbeerta, P. (2010). Long-term patterns of offending in women. Feminist Criminology, 5(1), 73-107. doi:10.1177/1557085109356520.

19. Bohensky, M. A., Jolley, D., Sundararajan, V., Evans, D., Ibrahim, J., \& Brand, C. (2011). Reporting guidelines for studies involving data linkage. Australian and New Zealand Journal of Public Health, 35, 486-489.

20. Bongers, I. L., Koot, H. M., Van der Ende, J., \& Verhulst, F. C. (2004). Developmental trajectories of externalizing behaviors in childhood and adolescence. Child Development, 75, 1523-1537.

21. Bowring, B. D., \& Little, A. (2009). Fetal alcohol syndrome and fetal alcohol spectrum disorder in Indigenous schoolchildren. The Medical Journal of Australia, 190, 286-287.

22. Brownell, M., Roos, N., Fransoo, R., et al. (2006). Is the class half empty?: a population-based perspective on socioeconomic status and educational outcomes. Montreal: Institute for Research on Public Policy Choices.

23. Burgess-Proctor, A. (2006). Intersections of race, class, gender, and crime: future directions for feminist criminology. Feminist Criminology, 1, 27-47.

24. Cohen, M. A., Piquero, A. R., \& Jennings, W. G. (2010). Monetary costs of gender and ethnicity disaggregated group-based offending. American Journal of Criminal Justice, 35, 159-172.

25. Corrado, R. R., Kuehn, S., \& Margaritescu, I. (2014). Policy issues regarding the over-representation of incarcerated Aboriginal young offenders in a Canadian context. Youth Justice, 14, 40-62.

26. D’Unger, A. V., Land, C. K., \& McCall, P. L. (2002). Sex differences in age patterns of delinquent/ criminal careers: results from Poisson latent class analyses of the Philadelphia Cohort Study. Journal of Quantitative Criminology, 18, 349-375.

27. DeLisi, M. (2002). Not just a boy's club: an empirical assessment of female career criminals. Women \& Criminal Justice, 13(4), 27-45.

28. DeLisi, M., \& Piquero, A. R. (2011). New frontiers in criminal careers research, 2000-2011: a state of the art review. Journal of Criminal Justice, 39, 289-301.

29. Dennison, S., Stewart, A., \& Hurren, E. (2006). Police cautioning in Queensland: the impact of juvenile offending on pathways. Trends \& Issues in Crime and Criminal Justice, no. 306. Canberra: Australian Institute of Criminology.

30. Dennison, S., Stewart, A., \& Freiberg, K. (2013). A prevalence study of children with imprisoned fathers: annual and lifetime estimates. Australian Journal of Social Issues, 48(3), 339-362.

31. Doherty, E. E., \& Ensminger, M. E. (2014). Do the adult criminal careers of African Americans fit the "facts"? Journal of Criminal Justice, 42, 517-526.

32. Donnellan, M. B., Ge, X., \& Wenk, E. (2000). Cognitive abilities in adolescence-limited and life-coursepersistent criminal offenders. Journal of Abnormal Psychology, 109, 727-704.

33. Eggleston, E. P., \& Laub, J. H. (2002). The onset of adult offending: a neglected dimension of the criminal career. Journal of Criminal Justice, 30, 603-622.

34. Farrington, D. P. (2005). Childhood origins of antisocial behavior. Clinical Psychology \& Psychotherapy, 12, 177-190.

35. Farrington, D. P. (2003). Developmental and life-course criminology: key theoretical and empirical issues - the 2020 Sutherland Award Address. Criminology, 41, 221-255.

36. Farrington, D. P. \& Painter, K. (2004). Gender differences in risk factors for offending. London: Home Office. (Research Findings No. 196). http://www.crim.cam.ac.uk/people/academic_research/david_ farrington/hofind196.pdf

37. Farrington, D. P., Ttofi, M. M., \& Coid, J. W. (2009). Development of adolescence-limited, late-onset, and persistent offenders from age 8 to age 48. Aggressive Behavior, 35, 150-163.

38. Fergusson, D., Horwood, L., \& Nagin, D. (2000). Offending trajectories in a New Zealand birth cohort. Criminology, 38(2), 525-551.

39. Fergusson, D. M., \& Horwood, L. J. (2002). Male and female offending trajectories. Development and Psychopathology, 14, 159-177.

40. Ferrante, A. (2013). Assessing gender and ethnic differences in developmental trajectories of offending. Australian and New Zealand Journal of Criminology, 46(3), 379-402.

41. Ferrante, A., Morgan, F., Indermaur, D., \& Harding, R. (1996). Measuring the extent of domestic violence. Sydney: Hawkins.

42. Fitzgerald, R., Mazerolle, P., Piquero, A., \& Ansara, D. (2012). Exploring sex differences among sentenced juvenile offenders in Australia. Justice Quarterly, 29(3), 420-447. 
43. Fontaine, N., Carbonneau, R., Vitaro, F., Barker, E. D., \& Tremblay, R. E. (2009). Research review: a critical review of studies on the developmental trajectories of antisocial behavior in females. The Journal of Child Psychology and Psychiatry, 50, 363-385.

44. Giordano, P. C., Cernkovich, S. A., \& Rudolph, J. L. (2002). Gender, crime, and desistance: toward a theory of cognitive transformation. American Journal of Sociology, 107, 990-1064.

45. Hartney, C., \& Vuong, L. (2009). Created equal: racial and ethnic disparities in the US criminal justice system. Oakland: National Council on Crime and Delinquency.

46. Hawkins D. F., Laub, J. H. Lauritsen, J. L. \& Cothern, L. (2000). Race, ethnicity and serious and violent juvenile offending. Juvenile Justice Bulletin. Office of Juvenile Justice and Delinquency Prevention. https://www.ncjrs.gov/html/ojjdp/2000_6_1/contents.html

47. Haynie, D. L., \& Armstrong, D. P. $(200 \overline{6})$. Race- and gender-disaggregated homicide offending rates: differences and similarities by victim-offender relations across cities. Homicide Studies, 10, 3-32.

48. Haynie, D. L., Weiss, H. E., \& Piquero, A. (2008). Race, the economic maturity gap, and criminal offending in young adulthood. Justice Quarterly, 25(4), 595-622.

49. Hill-Collins, P. (2000). Black feminist thought: knowledge, consciousness, and the politics of empowerment (2nd ed.). New York: Routledge.

50. Hill-Collins, P. (2004). Black sexual politics: African Americans, gender, and the new racism. New York: Routledge.

51. Jennings, W. G., Zgoba, P. M., Piquero, A. R., \& Reingle, J. M. (2013). Offending trajectories among native-born and foreign-born Hispanics to late middle age. Sociological Inquiry, 83, 622-647.

52. Jones, B. L., Nagin, D. S., \& Roeder, K. (2001). A SAS procedure based on mixture models for estimating developmental trajectories. Sociological Methods \& Research, 29(3), 374-393. doi:10.1177/ 0049124101029003005.

53. Jutte, D. P., Roos, L. L., \& Brownell, M. D. (2011). Administrative record linkage as a tool for public health research. Annual Review of Public Health, 32, 91-108.

54. Khalidi, N., McGill, K., Houweling, H., Arnett, K., \& Sheahan, A. (2012). Closing the gap in low birthweight births between Indigenous and non-Indigenous mothers, Queensland. Statbite \#46. Brisbane: Queensland Health.

55. Kieger, N. (1992). Overcoming the absence of socioeconomic data in medical records: validation and application of a census-based methodology. American Journal of Public Health, 82, 703-710.

56. Kratzer, L., \& Hodgins, S. (1999). A typology of offenders: a test of Moffitt's theory among males and females from childhood to age 30. Criminal Behaviour and Mental Health, 9, 57-73.

57. Kruttschnitt, C. (2013). Gender and crime. Annual Review of Sociology, 39, 291-308.

58. Landsheer, J. A., \& van Dijkum, C. (2005). Male and female delinquency trajectories from pre through middle adolescence and their continuation in late adolescence. Adolescence, 40, 729-748.

59. Laub, J. H., \& Sampson, R. L. (2003). Shared beginnings, divergent lives: delinquent boys to age 70. Boston: Harvard University Press.

60. Little, S., Allard, T., Chrzanowski, A and Stewart, A. (2011). Diverting young Indigenous people from the Queensland youth justice system: the use and impact of police diversionary practices and alternatives for reducing Indigenous over-representation. Indigenous Criminal Justice Research Agenda report. Queensland Government.

61. Livingston, M., Stewart, A., Allard, T., \& Ogilvie, J. (2008). Understanding juvenile offending trajectories. Australian and New Zealand Journal of Criminology, 41(3), 345-363. doi:10.1375/acri.41.3.345.

62. Loh, N., \& Ferrante, A. (2003). Aboriginal involvement in the Western Australian criminal justice system: a statistical review, 2001. Perth: University of Western Australia, Crime Research Centre.

63. Maldonado-Molina, M. M., Piquero, A. R., Jennings, W. G., Bird, H., \& Canino, G. (2009). Trajectories of delinquency among Puerto Rican children and adolescents at two sites. Journal of Research in Crime and Delinquency, 46, 144-181.

64. Markowitz, M. W., \& Salvatore, C. (2012). Exploring race based differences in patterns of life-course criminology. Deviant Behavior, 33, 589-605.

65. Marshall, J. (2006). Juvenile offending trajectories: a South Australian study. Adelaide: Office of Crime Statistics and Research.

66. Maruna, S. (2004). Desistance from crime and explanatory style: a new direction in the psychology of reform. Journal of Contemporary Criminal Justice, 20, 184-200.

67. McGee, T. R., \& Farrington, D. P. (2010). Are there any true adult-onset offenders? British Journal of Criminology, 50, 530-549.

68. Miller, J. (1998). Up it up: the accomplishment of street robbery. Criminology, 36, 37-66.

69. Miller, J. (2001). One of the guys: girls, gangs and gender. New York: Oxford University Press. 
70. Miller, S., Malone, P. S., \& Dodge, K. A. (2010). Developmental trajectories of boys' and girls' delinquency: sex differences and links to later adolescent outcomes. Journal of Abnormal Child Psychology, 38, 1021-1032.

71. Moffitt, T. E. (1993). Adolescence-limited and life-course-persistent antisocial behavior: a developmental taxonomy. Psychological Review, 100, 647-701.

72. Moffitt, T. E. (1994). Natural histories of delinquency. In E. G. M. Weitekamp \& H. Kerner (Eds.), Cross-national longitudinal research on human development and criminal behavior (pp. 3-61). Dordrecht: Kluwer Academic.

73. Moffitt, T. E. (2003). Life-course persistent and adolescence-limited antisocial behavior: a 10 year research review and a research agenda. In B. Lahey, T. E. Moffitt, \& A. Caspi (Eds.), The course of conduct disorder and serious juvenile delinquency (pp. 49-75). New York: Guildford.

74. Moffitt, T. E. (2006). Life-course-persistent versus adolescent-limited antisocial behavior. In D. Cicchetti \& D. J. Cohen (Eds.), Developmental psychopathology, risk disorder and adaptation (pp. 570-596). New York: Wiley.

75. Moffitt, T., \& Caspi, A. (2001). Childhood predictors differentiate life-course persistent and adolescentlimited antisocial pathways among males and females. Development and Psychopathology, 13, 355-375.

76. Nagin, D. S. (1999). Analyzing developmental trajectories: a semiparametric group-based approach. Psychological Methods, 4(2), 139-157.

77. Nagin, D., \& Land, L. (1993). Age, criminal careers, and population heterogeneity: specification and estimation of a nonparametric, mixed Poisson model. Criminology, 31(3), 327-362.

78. Nagin, D. S., \& Odgers, C. L. (2010). Group-based trajectory modeling (nearly) two decades later. Journal of Quantitative Criminology, 26, 445-453.

79. Odgers, C. L., Moffitt, T. E., Broadbent, J. M., Dickson, N., Hancox, R. J., \& Harrington. (2008). Female and male antisocial trajectories: from childhood origins to adult outcomes. Development and Psychopathology, 20(2), 673-716. doi:10.1017/s0954579408000333.

80. Office of Economic and Statistical Research (2010). Synthetic populations estimates by Indigenous status, 2000 to 2010. Retrieved from http://www.oesr.qld.gov.au/subjects/demography/atsi-people/tables/ synthetic-pop-est-indigenous-status/index.php

81. Peterson, R. D., \& Krivo, L. J. (2010). Divergent social worlds: neighborhood crime and the racialspatial divide. New York: Russell Sage (American Sociological Association's Rose Monograph Series).

82. Piquero, A., \& Buka, S. (2002). Linking juvenile and adult patterns of criminal activity in the Providence cohort of the National Collaborative Prenatal Project. Journal of Criminal Justice, 30, 259-272.

83. Piquero, A. R., \& Chung, H. L. (2001). On the relationships between gender, early onset, and the seriousness of offending. Journal of Criminal Justice, 29, 189-206.

84. Piquero, A., Moffitt, T., \& Lawton, B. (2005). Race differences in life-course-persistent offending. In D. F. Hawkins \& K. Kempf-Leonard (Eds.), Our children, their children: race/ethnicity and crime (pp. 202244). Chicago: University of Chicago Press.

85. Pyke, K. D., \& Johnson, D. L. (2003). Asian American women and racialized femininities: "doing" gender across cultural worlds. Gender and Society, 17, 33-53.

86. Sampson, R. J., \& Laub, J. H. (1993). Crime in the making: pathways and turning points through life. Boston: Harvard University Press.

87. Simpson, S. S. (1991). Caste, class, and violent crime: explaining difference in female offending. Criminology, 29, 115-135.

88. Simpson, S. S., \& Elis, L. (1995). Doing gender: sorting out the caste and crime conundrum. Criminology, 33, 47-81.

89. Skrzypiec, G., \& Wundersitz, J. (2005). Young people born 1984: extent of involvement with the juvenile justice system. Adelaide: South Australia Office of Crime Statistics and Research.

90. Soothill, K., Ackerley, E., \& Francis, M. (2003). The persistent offenders debate: a focus on temporal changes. Criminal Justice, 3, 389-412.

91. Steffensemeier, D., Feldemeyer, B., Harris, C. T., \& Ulmer, J. T. (2011). Reassessing trends in Black violent crime, 1980-2008: sorting out the "Hispanic effect" in uniform crime reports arrests, national crime victimization survey offender estimates, and U.S. prisoner counts. Criminology, 49, 197-251.

92. SCRGSP: Steering Committee for the Review of Government Service Provision (2009). Overcoming indigenous disadvantage: key indicators 2009. Productivity Commission: Canberra.

93. Thompson, C., Stewart, A., Allard, T., Chrzanowski, A., Luker, C., \& Sveticic, J. (2014). Examining adultonset offending: a case for adult cautioning. Trends \& Issues in Crime and Criminal Justice, 488, 1-8.

94. Thornberry, T. P. (1987). Toward an interactional theory of offending. Criminology, 25, 863-892. 
95. Thornberry, T. P., \& Krohn, M. D. (2005). Applying interactional theory to the explanation of continuity and change in antisocial behavior. In D. P. Farrington (Ed.), Integrated developmental and life course theories of offending (pp. 183-210). New Brunswick: Transaction.

96. Weatherburn, D. (2014). Arresting incarceration: pathways out of Indigenous imprisonment. Canberra: Aboriginal Studies Press.

97. Weatherburn, D., Fitzgerald, J., \& Hua, J. (2003). Reducing aboriginal over-representation in prison. Australian Journal of Public Administration, 62, 65-73.

98. West, C., \& Fenstermaker, S. (1995). Doing difference. Gender and Society, 9, 8-37.

99. White, N. A., \& Piquero, A. (2004). A preliminary empirical test of Silverthorn and Frick's delayedonset pathway in girls using an urban, African-American, US-based sample. Criminal Behaviour and Mental Health, 14, 291-309.

100. Wikstrom, P. H. (1990). Age and crime in a Stockholm cohort. Journal of Quantitative Criminology, 6, 61-84.

101. Yessine, A. K., \& Bonta, J. (2009). The offending trajectories of youth aboriginal offenders (pp. 435472). Canada: Public Safety.

102. Zara, G., \& Farrington, D. P. (2009). Childhood and adolescent predictors of late onset criminal careers. Journal of Youth and Adolescence, 38, 287-300. 